\title{
Review Article \\ Understanding the Mechanisms of Recovery and/or Compensation following Injury
}

\author{
Michael J. Hylin, ${ }^{1}$ Abigail L. Kerr, ${ }^{2}$ and Ryan Holden ${ }^{1}$ \\ ${ }^{1}$ Neurotrauma and Rehabilitation Laboratory, Department of Psychology, Southern Illinois University, Carbondale, IL, USA \\ ${ }^{2}$ Department of Psychology, Illinois Wesleyan University, Bloomington, IL, USA \\ Correspondence should be addressed to Michael J. Hylin; mhylin@siu.edu
}

Received 19 December 2016; Revised 24 February 2017; Accepted 26 March 2017; Published 20 April 2017

Academic Editor: Andrea Turolla

Copyright ( 2017 Michael J. Hylin et al. This is an open access article distributed under the Creative Commons Attribution License, which permits unrestricted use, distribution, and reproduction in any medium, provided the original work is properly cited.

\begin{abstract}
Injury due to stroke and traumatic brain injury result in significant long-term effects upon behavioral functioning. One central question to rehabilitation research is whether the nature of behavioral improvement observed is due to recovery or the development of compensatory mechanisms. The nature of functional improvement can be viewed from the perspective of behavioral changes or changes in neuroanatomical plasticity that follows. Research suggests that these changes correspond to each other in a bidirectional manner. Mechanisms surrounding phenomena like neural plasticity may offer an opportunity to explain how variables such as experience can impact improvement and influence the definition of recovery. What is more, the intensity of the rehabilitative experiences may influence the ability to recover function and support functional improvement of behavior. All of this impacts how researchers, clinicians, and medical professionals utilize rehabilitation.
\end{abstract}

\section{Recovery or Compensation}

One important question in the study of adult brain injury and repair is whether behavioral improvement reflects true behavioral recovery or whether the behavioral changes are simply due to the use of compensatory strategies in reaction to a disrupted nervous system. Part of the difficulty with recovery, from a clinical perspective, is in how it is defined. To a clinician, recovery may be generally defined in terms of improved behavior following an injury. Good recovery is defined by the Glasgow Outcome Scale as a "resumption of normal activities even though there may be minor neurological and psychophysical deficits" $[1,2]$. Therefore, from the clinical perspective, an individual is "recovered" if they are able to show some improvement in functioning independently $[3,4]$. Still, defining recovery as simply returning to normal life is a fairly limited concept in that it does not take into account whether the individual is simply compensating for their lost behaviors. Foroud and Whishaw [5] analyzed the kinematic profiles of two stroke patients during a reaching task and found that while the patients were able to perform the task, they demonstrated kinematic abnormalities during reaching. Though in only two patients, this evidence of compensatory limb use suggests a qualitatively different functional outcome than true behavioral recovery. These qualitative differences are likely reflected in central nervous system structure and function, the effects of which may have long-term impacts on behavioral outcome.

Typically, the focus of rehabilitative treatments following stroke or traumatic brain injury is often upon encouraging the development of compensatory strategies in order to resume independent daily living [6-8]. For instance, individuals that are hemiplegic have difficulty using their impaired limbs and rehabilitative therapy may encourage the use of their unimpaired side. Patients may also use compensatory strategies to cope with cognitive impairments. For example, if an individual is impaired in their ability to remember, a clinician may encourage the use of a journal or diary to help them remember daily events [9-12]. However, in both of these examples, even though the individual may be equipped to return to daily independent living, their impairments are still present and may interfere with long-term functional outcome instead of focusing on encouraging the lost behavior to return; the focus is upon compensating for their loss. 
Essentially, the goal of rehabilitation is often focused on independence as opposed to the impairment, which may lead to improved behavioral function but prevent true behavioral recovery.

Up to this point, it could be argued that the scenarios discussed illustrate how individuals are able to compensate for the lost behavior. In fact, it is important to point out that sometimes even when an individual appears to have "recovered" and is able to function independently, they may continue to show "silent" cognitive and motor deficits in areas such as emotion, attention, or fine motor control [13-19]. These deficits are important to take into consideration in discussing whether an individual has recovered as they may otherwise go ignored. Usually, depending upon the severity of the injury, deficits will abate over time, although some residual deficits may remain [20-22]. In fact, some authors have questioned whether it is possible to observe true recovery [23-25]. If we hope to improve the efficacy of rehabilitative strategies following brain injury, it is important to distinguish between true recovery and compensation and to understand the consequences of each for long-term neural and behavioral function. This review focuses on the anatomical and behavioral mechanisms surrounding the distinction between recovery and compensation in the adult with the aim of using this distinction to guide strategies for successful rehabilitation. As the majority of human strokes are ischemic in nature, we focus specifically on ischemic insult in the adult (human, nonhuman primate, and rodent models) [26]. Traumatic brain injuries (TBI) have a fairly distinct pathological response that is separate from stroke $[27,28]$. While within TBI characterization, focal and diffuse injuries have distinct pathologies; most TBIs have elements of both types of injury and are heterogeneous in nature making the distinction difficult from the perspective of recovery and treatment [29-31]. In addition, traumatic axonal injury has been shown to lead to selective atrophy in a regional manner similar to what is observed following focal injury [32]. This review considers how the cognitive reserve applies to functional improvement following injury and how the intensity of rehabilitation plays a role in recovery and compensation.

\section{Neuroanatomical Effects of Damage upon Recovery/Compensation}

In understanding how compensatory strategies are developed, one must consider the anatomical and cellular events that are associated with injury. Following unilateral brain injury, there is a sequence of events that have devastating effects upon the primary site of damage. Regardless of how the damage occurs (e.g., ischemic stroke or TBI), this usually begins with the interruption of the blood supply to the brain, which causes cells to die through over excitation due to excess glutamate release [33-38]. Following the initial damage, tissues become swollen and inflamed, compromising the integrity of areas that are distant from the primary site of damage [37, 39-42]. This swelling and inflammation may cause deficits that will abate over time $[43,44]$. There is also a decrease in the metabolic activity in the ipsilesional hemisphere suggesting that the damage can impact areas distal to the injury, a phenomenon known as diaschisis [45-47].

While injury results in devastating events, it also induces a cascade of growth-related events that enable remaining neurons near and distant to the lesion locus to survive, repair, and form new connections [48-53]. Some researchers have even proposed that some of the events that occur following damage are similar to what is observed during normal development, possibly suggesting that the brain has an intrinsic ability to react to change [54-59]. Changes in perilesion cortex (i.e., the area of vulnerable but surviving tissue immediately around the lesion core), including cortical reorganization, neurogenesis, axonal sprouting, dendritic plasticity, and angiogenesis, have been linked to spontaneous recovery of behavioral deficits following the resolution of diaschisis as described above [60-65]. Within the perilesion area, there is also an increase in the expression of growth-promoting genes which begins to be seen shortly after injury $[66,67]$. This altered environment is arguably becoming growth permissive, as increased axonal sprouting will occur in this region [53, 68]. Increased levels of GAP-43, a marker for the presence of growth cones, have been observed shortly after injury [69, 70]. Carmichael and Chesselet [71] found that the increased axonal sprouting correlates with an altered physiological response in the perilesion area. This increase in synchronous activity is followed by activity in other cortical regions associated with the damaged area including the contralesional homotopic cortex. Further, it is likely that the axonal sprouting and altered activity in this region is what underlies reorganization of the remaining cortical representations in the perilesion area [42, 68, 71-75].

The perilesion area is not the only location that is altered in response to injury. Frost et al. [21] found that following lesions of the hand area of the primary motor cortex in primates, there is an expansion of the hand area of the ventral premotor cortex (PMv) in the same hemisphere [76]. This increased expansion is associated with altered axonal sprouting from the PMv $[72,77]$. Both of these changes are correlated with improved motor behavior. Following injury, the contralesional hemisphere also exhibits an increase in dendritic growth [78-80] as well as increased sprouting of corticostriatal axons [78, 81]. Further, reorganization of contralesional hemisphere usually corresponds to increased synapse number $[82,83]$. Some authors have suggested that this growth is the result of a compensatory behavioral response (e.g., $[80,84])$.

Compensatory sprouting has also been looked at in models of TBI, as diffuse axonal injury is frequently observed following injury. The temporal lobes and hippocampus are one of the most vulnerable areas after a TBI $[85,86]$. Injury results in robust neural plastic changes in the hippocampus, which include increased synaptogenesis, increased expression plasticity-related proteins such as extracellular signal-regulated kinase, and altered expression of genes associated with structural changes [87-93]. However, it remains to be determined if these changes reflect a positive impact following injury and if methods inducing recovery could employ them to support improved outcome. Utilizing a model of combined TBI with entorhinal cortex deafferentation, 
Philips et al. (1994) observed cognitive deficits (impairments in the water maze) that were associated with aberrant neural sprouting and synapse formation. Damage to the entorhinal cortex has been shown to produce reactive synaptogenesis and collateral sprouting and result in the formation of novel synapses in the dentate gyrus [94-96]. In patients following TBI, compensatory neural tracts extending from the contralesional fornix have been observed and may underlie recovery of memory impairments [97].

It appears that the brain is able to undergo neuroanatomical changes that lead to the reorganization of remaining tissue following damage. However, this reorganization has behavioral consequences that need to be considered when determining whether recovery or compensation has occurred.

\section{Behavioral Effects of Recovery/Compensation}

Instead of regarding recovery as a "general" improvement in behavioral functioning, researchers have a more varied and sometimes less well-defined criterion. One view of behavioral recovery is whether an end point has been achieved that is similar to the preoperative performance of the animal or to the performance of a nonlesioned animal [22, 98-100]. For instance, if an animal is able to learn to navigate a maze successfully, even if it takes more trials to learn than an intact control, one could argue that the animal has demonstrated functional recovery [101-104]. A similar result is seen with animals that have received motor cortex lesions. Initially animals are impaired in their ability to reach for food, but they will eventually be able to successfully improve their reaching behavior following weeks of testing [105]. However, it is important to point out that while they are able to become more successful over time they are still impaired relative to even their own preoperative baseline [24]. Depending upon the task, animals usually show some improvement in behavior over time, possibly suggesting that some form of "recovery" may be possible $[106,107]$. It should be noted that with focused training of the impaired limb, animals often reach preoperative performance levels [108-111], suggesting that behavior can interact with naturally occurring plastic changes following stroke to drive functional outcome.

Often, behavioral changes are associated with the presence of neuroanatomical changes in areas functionally related to the damage. Following a unilateral lesion of the sensorimotor cortex, there is an increased reliance upon the unimpaired limb for movement and postural support which coincides with increased dendritic growth in the contralesional hemisphere $[46,47,79]$. The increased growth peaks at three weeks following injury, and pruning of this over growth begins to occur over the next few weeks. The overreliance on the unimpaired limb will also begin to decrease shortly after the dendritic pruning begins, possibly suggesting that the behavior of the animal over time following injury influences the ability for plasticity to occur [103, 112]. Jones and Schallert [80] tested this by restricting the movement of the unimpaired limb and forcing the animal to use their impaired limb. By restricting the unimpaired limb, the increased growth was blocked suggesting that the plasticity that occurs due to injury interacts with the behavioral deficit $[80,113]$. Similar results have been found in rodent models of TBI, although the mechanistic differences remain to be elucidated [114-117]. Although it is tempting to suggest that the increased neuronal growth that is observed following damage is beneficial as it is seen following improvements in behavior, it is possible that the growth is promoting compensatory behaviors rather than true recovery $[24,118,119]$, which may be interfering with or even preventing true recovery [84, 109, 120-122].

Forced use of the unimpaired limb following stroke, mimicking compensatory use following injury, is associated with decreased neuronal activation $[123,124]$ and further reduction of forelimb movement representations in the perilesion cortex [84]. Kim and colleagues report not only decreased forelimb representation area in perilesion motor cortex but also an increase in axodendritic synapses and multiple synaptic boutons following forced use of the unimpaired limb (i.e., compensatory limb training) [84]. This synaptic density negatively correlated with functional outcome of the impaired limb, suggesting that aberrant synaptogenesis, potentially of transcallosal projections, may contribute to the poor functional outcome associated with compensatory limb use following injury. Interestingly, animals that have had callosal transections do not exhibit the compensatory limb effect, with forced use of the unimpaired limb having no impact on bad limb recovery [122].

Another way experimental researchers define recovery is by whether the means (i.e., methods) to achieve a particular end point following injury is similar to how it would be performed in the intact animal [104]. Following injury, there is an emergence of what has been regarded as "self-taught" behaviors that develop spontaneously as behavioral deficits begin to subside. These behaviors may develop as a response to compensate for those behaviors lost as a result of injury $[125,126]$. For instance, following an ischemic injury to the motor cortex, squirrel monkeys are unable to use their affected hand in reaching for a pellet of food [64]. Over time, there is a gradual return in the ability to use the limb, and this improvement corresponds to reorganization of the motor map $[21,72,77,127]$. However, recovery of limb movement is due to the use of compensatory behavioral strategies that are fundamentally different from preinjury strategies [128-130]. Even more careful analysis has demonstrated that although the ability to grasp has returned, there are residual fine motor deficits that lead to the development of compensatory movement of individual digits despite further training $[73,131,132]$.

In a similar vein, injury to the motor cortex in rats results in an inability to successfully reach for a food pellet that abates over time. Rats with motor cortex lesions are unable to make rotational movements and demonstrate impaired digit use [24]. A more detailed analysis of the reaching behavior in rodents also suggests that even though lesioned animals may regain use of the impaired limb, many qualitative aspects of the behavior are different [133]. Further, a return of the reaching ability in the rat occurs in distinct stages [134].

In the acute stage following ischemic injury, lesioned animals are unsuccessful at their reaching attempts. 
Erickson et al. [135] suggested that animals are in a sense "learning" that they are likely to be unsuccessful in reaching for the pellet as there is a decline in the number of reaching attempts during this period. This "learned nonuse" occurs only in the acute stages following damage; 8 days post damage, rats increase their number of reach attempts [135]. As animals show an increase in their number of reach attempts, there is a corresponding increase in the number of individually repeated gestures. An animal may advance its limb and withdraw several times without ever grasping the food. Even though there is an increase in the number of attempts, if there is a reduction in the number of successful reaches due to the additional gestures, this behavior could be characterized as "learned bad-use" [136, 137]. Encouraging the unimpaired limb to be used can interfere with later training of the impaired limb $[109,111,120,123,138]$. It is possible that remaining motor systems take advantage of the beneficial growth that occurs following ischemic injury, which leads to increased use of the unimpaired limb. Interestingly, bilateral limb use (via either focused, skilled training or home-cage enrichment that encourages dexterous use of both limbs) ameliorates this effect, resulting in a restoration of rehabilitative potential of the impaired limb [109, 123].

It may also be possible for behavioral substitution to take place following injury-induced loss of behavior. Rauschecker [139] found that cats that were deprived of vision early in life can solve a visual maze using tactile sensation that is complimented by expanded cortical representation of their facial vibrissae. Therefore, in the absence of one means for solving a task, it appears that another can substitute and allow for the goal to be accomplished via sensory substitution or a different behavioral strategy. Whishaw et al. [140] demonstrated that hemidecorticate rats are able to learn to successfully navigate a maze, which may suggest that different strategies, possibly mediated by subcortical areas, can be substituted in order for them to successfully navigate. This result is not to be unexpected considering rats are able to substitute one spatial strategy in the absence of another in order to successfully navigate an environment [141].

Part of the difficulty of determining whether true recovery has occurred in the experimental setting has been in the analysis of the behavior. Some authors have even stated that using just a few (often only one) behavioral measures may lead to biased estimates of behavior and that a better assessment of behavior comes from using a "battery" of speciestypical and learned behaviors [105]. The use of simple "end point" measures also limits the interpretation of whether a motor behavior has returned [134, 136, 142]. Further, the fractionation of more complex behaviors (e.g., reaching) enables researchers to determine what is possible with regard to recovery and whether animals are using compensatory behaviors [134, 143].

As mentioned previously, most rehabilitative treatments encourage the use of compensatory strategies following injury. However, there are clinical studies of rehabilitative therapies for motor deficits that have focused on training the impaired limb following stroke [144-147]. Some researchers have suggested that what is observed during natural recovery is the development of compensatory behaviors and that "true" recovery is possible following specific rehabilitative training focused on the impairment rather than behavioral outcome $[148,149]$. Still, other researchers have taken an extreme stance on the issue suggesting that when recovery is observed, it is due to the reorganization of remaining areas that lead to the development of compensatory behaviors [24]. Even if the behavior is similar to preinjury conditions, the argument is that the remaining functional areas now have to compensate for the loss. Therefore, this argument posits that in order for true recovery to occur, the neurons and their corresponding neural connections that were lost during injury need to be replaced rather than substituted $[24,150]$.

\section{The Role of Reserve after Brain Injury}

In the field of brain injury, there remains a clear disconnect between brain trauma severity and clinical emergence $[151,152]$. A similar brain injury among two, separate individuals may not result in the same degree of behavioral impairments. It has been proposed that this observation could be a result of individual differences in a concept known as cognitive reserve. Cognitive reserve (CR) is considered to be an accumulation of complex neural networks that allows for unique task processing in the brain [153]. CR can be increased through a variety of mental activities that keep the brain active. In other words, "exercising" or strengthening the brain's neuronal connections leads to a large CR. This "exercise" works to provide the brain with a more plastic and varied neural circuitry. CR has been associated with characteristics such as a balanced diet, occupational complexity [154], IQ [152], and participation in various lifestyle activities [155]. According to Murray et al. [156], level of education can also be used as a marker for cognitive reserve. As such, studies have shown that those with high levels of educational attainment have been associated with greater short- and long-term functional recovery after brain injury, in cases of both ischemic stroke [157] and moderate/severe traumatic brain injuries $[158,159]$.

Another hypothesis that has been put forth is that cognitive reserve is based upon one's entire lifetime. If this is the case, then older individuals should, in theory, have more cognitive reserve capacity than younger individuals since they have had longer to fully develop their more elaborate and intricate communicative system. Although, it must be pointed out that the brain processing in those with high CR is the same for all individuals [153]. The capacity of CR may vary, but its way of action does not change. A larger CR would give an individual a higher threshold for injury and would require an injury of greater severity for clinical symptoms to show [152]. However, research has shown that CR positively influences functional recovery not only in adults but also in children and adolescents [158]. It would seem that a larger CR, at any age or time point during development, could help the brain to better sustain injuries [160]. Although, the literature also suggests that a CR of lower capacity can exacerbate the secondary effects of brain injuries, particularly in instances of TBIs [158]. Therefore, CR may serve as a preventative compensatory mechanism in 
order to keep the injury from producing further and unnecessary damage after brain injury.

There is the possibility that cognitive reserve may be acting as the nervous system's natural means of compensation after brain injury. Specifically, a large cognitive reserve could provide a more convenient outlet for plasticity to occur, allowing for the more efficient and established neural connections to help the brain better sustain injuries because of its higher level of threshold $[159,161]$. In addition to compensatory action through an emphasis on well-established connections, individuals that accumulate a strong CR throughout their lifetime may have a brain that is unique in neural organization in another way, such that the brain communicates in a more holistic manner through a more varied neural network rather than through a limited number of possible neuronal pathways [154]. Since the level of redundancy is high in those with a large CR, it is unlikely that a brain injury will disrupt all communicative routes, thereby fostering a quicker, less intrusive cognitive recovery through the utilization of alternative neural circuitry [162]. It remains to be shown if cognitive reserve is a form of preventive compensation (i.e., the brain is compensating for natural loss because there is synaptic loss as we age and neurons compensate for the loss by increasing synaptic number) [163]. But if there is an injury, this compensation from natural aging gets used up.

\section{The Impact of Timing and Intensity on Rehabilitation Efficacy}

Following CNS injury, experience-induced plasticity (e.g., changes induced via rehabilitation) interacts with the natural richly plastic environment described above. The ultimate efficacy of rehabilitative training depends on how well coordinated those plastic events are. There are a number of factors that may drive more functionally beneficial effects of rehabilitative training, including the timing and intensity of training.

As we have discussed, the injured brain can both promote and inhibit neural plasticity. In order to maximize the functional benefit of rehabilitative training, the timing of training onset must coincide with a naturally more growth permissive environment following injury. Identifying the ideal "window of recovery" following injury is difficult, though research in rodents suggests that there is an early vulnerable period following injury during which training can have negative effects on recovery and exacerbate neural damage. For instance, forced use of the impaired forelimb during the first seven days following stroke results in poor functional outcome and larger lesion size compared to rats permitted to engage either forelimb [164-166]. Similar results are found with exercise as a rehabilitative strategy, with early exercise reducing neuroplasticity-related molecules in the hippocampus following traumatic brain injury in rats. More favorable outcomes are reported if the exercise is initiated two weeks following TBI, with the same molecules being upregulated and spatial memory improving [167, 168]. Early exercise can also be problematic following ischemic stroke causing increased apoptosis and impaired learning performance $[169,170]$.

When is the best time to introduce rehabilitative training - the question is somewhat difficult. Biernaskie and colleagues found that rehabilitative training was more effective in improving behavioral outcome when initiated five days rather than 30 days following stroke [171]. Similar results were reported by Norrie et al. [172], who found that though stepping function in rats improved after motor rehabilitative training initiated both immediately after spinal cord injury and after a three-month delay, the immediate rehabilitation was much more efficacious. Early onset training is also more beneficial to structural plasticity; motor maps in monkeys exhibit decreased sparing of movement representation areas in the motor cortex when training is initiated one month after ischemic cortical infarct rather than one week [173]. Together, these findings suggest that the ideal time to introduce symptom-specific, skilled rehabilitative training is early, but not immediately, after insult. However, the exact time window for beneficial structural and functional outcomes is still unclear. It is important that we continue to explore the regenerative and degenerative responses of the brain to injury and how these responses interact with behaviorally induced experience-dependent plasticity to drive functional outcome.

Another factor that affects behavioral outcome following injury is the intensity of rehabilitative training. In the intact brain, training intensity impacts both the rate of behavioral change as well as the neural consequences associated with new learning. For instance, mice that receive twice daily motor skill training sessions exhibit a faster acquisition of the skill [174]. MacLellan and colleagues (2011) found that enriched rehabilitation (skilled reaching combined with enriched housing) was only effective in improving functional recovery when enrichment was provided during the more active dark cycle, when rats are more likely to engage with enrichment options at higher intensity [175]. The researchers suggest that there may be a threshold of rehabilitation that is necessary to provide functional benefits. Similarly, Bell et al. [108] found that twice-daily training on the Pasta Matrix Reaching Task (i.e., skilled rehabilitative training) was more beneficial for functional outcome than once-daily training sessions. Specifically, high-intensity training resulted in a faster return to preoperative performance levels [108]. Results from these studies suggest that high-intensity rehabilitative training, initiated early after insult, would be the most effective strategy to employ in humans. It should be noted that current rehabilitative regimens in humans are considerably less intense than those practiced in animal models [22].

\section{Conclusions}

Although the proceeding discussion has focused on compensation/recovery following injury, it is likely that these mechanisms reflect a natural phenomenon that allows an organism to constantly adapt to an ever-changing environment rather than exclusively occurring following injury. While this is a novel consideration in understanding compensation, it has its basis in the observation of what occurs 
during learning and may reflect the nervous system's ability to adapt to an ever-changing environment (i.e., experiencedependent plasticity). In most normal situations for solving a task, there is a hierarchy of behaviors in order to successfully complete it. If, for instance, an individual is blindfolded, they may still be able to complete a maze through the use of tactile or auditory cues [98]. Also, if a "normal" individual is blindfolded and taught to tacitly discriminate for a prolonged period, there is a temporary increase in activity present in the occipital cortex when tactile stimulation is given [176].

The plastic changes that occur following injury are strikingly similar to those that are observed in normal brains following learning or other experiences [105, 177]. For instance, training of a particular motor sequence induces an altered representation in a normally functioning nervous system that is similar to what occurs following damage $[178,179]$. One explanation for this may be that the nervous system is able to change in response to behavioral demand. In many instances, plastic changes occur in at all levels of organization from gene expression to neural systems following injury or during "normal" training [180]. This may suggest that there is a common thread between what occurs following damage and what occurs in situations where plasticity normally occurs. Therefore, one possible method to understand the changes associated with recovery/compensation is observing situations where plasticity normally occurs. However, future work needs to focus on determining and defining what entails complete recovery and whether it is possible for it to occur naturally or through the use of therapeutic intervention or if compensation is the only possibility.

\section{Conflicts of Interest}

The authors declare that they have no conflicts of interest.

\section{References}

[1] B. Jennett and M. Bond, "Assessment of outcome after severe brain damage,” Lancet, vol. 1, no. 7905, pp. 480-484, 1975.

[2] T. McMillan, L. Wilson, J. Ponsford, H. Levin, G. Teasdale, and M. Bond, "The Glasgow Outcome Scale-40 years of application and refinement," Nature Reviews Neurology, vol. 12 , no. 8, pp. 477-485, 2016.

[3] R. Nakase-Richardson, J. Whyte, J. T. Giacino et al., "Longitudinal outcome of patients with disordered consciousness in the NIDRR TBI Model Systems programs," Journal of Neurotrauma, vol. 29, no. 1, pp. 59-65, 2012.

[4] D. G. Stein and M. M. Glasier, "An overview of developments in research on recovery from brain injury," in Recovery from Brain Damage: Reflections and Directions, F. D. Rose and D. A. Johnson, Eds., pp. 1-22, Plenum Press, New York, NY, 1992.

[5] A. Foroud and I. Q. Whishaw, "Changes in the kinematic structure and non-kinematic features of movements during skilled reaching after stroke: a Laban Movement Analysis in two case studies," Journal of Neuroscience Methods, vol. 158, no. 1, pp. 137-149, 2006.

[6] E. W. Twamley, K. R. Thomas, A. M. Gregory et al., "CogSMART compensatory cognitive training for traumatic brain injury: effects over 1 year," The Journal of Head Trauma Rehabilitation, vol. 30, no. 6, pp. 391-401, 2015.

[7] E. W. Twamley, A. J. Jak, D. C. Delis, M. W. Bondi, and J. B. Lohr, "Cognitive Symptom Management and Rehabilitation Therapy (CogSMART) for veterans with traumatic brain injury: pilot randomized controlled trial," Journal of Rehabilitation Research and Development, vol. 51, no. 1, pp. 59-70, 2014.

[8] S. E. Nadeau, B. Dobkin, S. S. Wu, Q. Pei, P. W. Duncan, and LEAPS Investigative Team, "The effects of stroke type, locus, and extent on long-term outcome of gait rehabilitation: the LEAPS experience," Neurorehabilitation and Neural Repair, vol. 30, no. 7, pp. 615-625, 2016.

[9] M. M. Sohlberg and C. A. Mateer, "Training use of compensatory memory books: a three stage behavioral approach," Journal of Clinical and Experimental Neuropsychology, vol. 11, no. 6, pp. 871-891, 1989.

[10] D. Shum, J. Fleming, H. Gill, M. J. Gullo, and J. Strong, "A randomized controlled trial of prospective memory rehabilitation in adults with traumatic brain injury," Journal of Rehabilitation Medicine, vol. 43, no. 3, pp. 216-223, 2011.

[11] A. McDonald, C. Haslam, P. Yates, B. Gurr, G. Leeder, and A. Sayers, "Google calendar: a new memory aid to compensate for prospective memory deficits following acquired brain injury," Neuropsychological Rehabilitation, vol. 21, no. 6, pp. 784-807, 2011.

[12] T. Bergquist, C. Gehl, J. Mandrekar et al., "The effect of internet-based cognitive rehabilitation in persons with memory impairments after severe traumatic brain injury," Brain Injury, vol. 23, no. 10, pp. 790-799, 2009.

[13] S. T. Pendlebury, F. C. Cuthbertson, S. J. Welch, Z. Mehta, and P. M. Rothwell, "Underestimation of cognitive impairment by mini-mental state examination versus the Montreal cognitive assessment in patients with transient ischemic attack and stroke: a population-based study," Stroke, vol. 41, no. 6, pp. 1290-1293, 2010.

[14] S. Weintraub, "Neuropsychological assessment of mental state," in Principles of Behavioral and Cognitive Neurology, M. M. Mesulam, Ed., pp. 121-173, Oxford University Press, New York, NY, 2000.

[15] S. Lai, A. Panarese, C. Spalletti et al., "Quantitative kinematic characterization of reaching impairments in mice after a stroke," Neurorehabilitation and Neural Repair, vol. 29, no. 4, pp. 382-392, 2015.

[16] S. K. Moon, M. Alaverdashvili, A. R. Cross, and I. Q. Whishaw, "Both compensation and recovery of skilled reaching following small photothrombotic stroke to motor cortex in the rat," Experimental Neurology, vol. 218, no. 1, pp. 145-153, 2009.

[17] G. A. Metz, I. Antonow-Schlorke, and O. W. Witte, "Motor improvements after focal cortical ischemia in adult rats are mediated by compensatory mechanisms," Behavioural Brain Research, vol. 162, no. 1, pp. 71-82, 2005.

[18] J. M. Smith, P. Lunga, D. Story et al., "Inosine promotes recovery of skilled motor function in a model of focal brain injury," Brain, vol. 130, part 4, pp. 915-925, 2007.

[19] M. Wang, H. Pu, Y. Liu, Z. Wang, B. Wang, and W. Xu, "A comparison of different models with motor dysfunction after traumatic brain injury in adult rats," Journal of Integrative Neuroscience, vol. 13, no. 4, pp. 579-593, 2014. 
[20] S. C. Cramer, R. R. Benson, V. C. Burra et al., "Mapping individual brains to guide restorative therapy after stroke: rationale and pilot studies," Neurological Research, vol. 25, no. 8, pp. 811-814, 2003.

[21] S. B. Frost, S. Barbay, K. M. Friel, E. J. Plautz, and R. J. Nudo, "Reorganization of remote cortical regions after ischemic brain injury: a potential substrate for stroke recovery," Journal of Neurophysiology, vol. 89, no. 6, pp. 3205-3214, 2003.

[22] J. W. Krakauer, S. T. Carmichael, D. Corbett, and G. F. Wittenberg, "Getting neurorehabilitation right: what can be learned from animal models?" Neurorehabilitation and Neural Repair, vol. 26, no. 8, pp. 923-931, 2012.

[23] P. Langhorne, J. Bernhardt, and G. Kwakkel, "Stroke rehabilitation," Lancet, vol. 377, no. 9778, pp. 1693-1702, 2011.

[24] I. Q. Whishaw, "Loss of the innate cortical engram for action patterns used in skilled reaching and the development of behavioral compensation following motor cortex lesions in the rat," Neuropharmacology, vol. 39, no. 5, pp. 788-805, 2000.

[25] F. E. Buma, M. Raemaekers, G. Kwakkel, and N. F. Ramsey, "Brain function and upper limb outcome in stroke: a crosssectional fMRI study," PLoS One, vol. 10, no. 10, article e0139746, 2015.

[26] Writing Group Members, D. Mozaffarian, E. J. Benjamin et al., "Heart disease and stroke statistics-2016 update: a report from the American Heart Association," Circulation, vol. 133, no. 4, pp. e38-e360, 2016.

[27] H. W. Phipps, "Systematic review of traumatic brain injury animal models," Methods in Molecular Biology, vol. 1462, pp. 61-88, 2016.

[28] S. T. Carmichael, "Rodent models of focal stroke: size, mechanism, and purpose," NeuroRx, vol. 2, no. 3, pp. 396-409, 2005.

[29] T. Skandsen, K. A. Kvistad, O. Solheim, I. H. Strand, M. Folvik, and A. Vik, "Prevalence and impact of diffuse axonal injury in patients with moderate and severe head injury: a cohort study of early magnetic resonance imaging findings and 1-year outcome," Journal of Neurosurgery, vol. 113, no. 3, pp. 556-563, 2010.

[30] P. E. Vos, "Biomarkers of focal and diffuse traumatic brain injury," Critical Care, vol. 15, no. 4, p. 183, 2011.

[31] T. M. Andriessen, B. Jacobs, and P. E. Vos, "Clinical characteristics and pathophysiological mechanisms of focal and diffuse traumatic brain injury," Journal of Cellular and Molecular Medicine, vol. 14, no. 10, pp. 2381-2392, 2010.

[32] M. A. Warner, T. S. Youn, T. Davis et al., "Regionally selective atrophy after traumatic axonal injury," Archives of Neurology, vol. 67, no. 11, pp. 1336-1344, 2010.

[33] A. Chodobski, B. J. Zink, and J. Szmydynger-Chodobska, "Blood-brain barrier pathophysiology in traumatic brain injury," Translational Stroke Research, vol. 2, no. 4, pp. 492-516, 2011.

[34] X. Wang, X. Bao, R. Pal, A. Agbas, and E. K. Michaelis, "Transcriptomic responses in mouse brain exposed to chronic excess of the neurotransmitter glutamate," BMC Genomics, vol. 11, no. 1, p. 360, 2010.

[35] L. P. Vera-Portocarrero, C. D. Mills, Z. Ye et al., "Rapid changes in expression of glutamate transporters after spinal cord injury," Brain Research, vol. 927, no. 1, pp. 104-110, 2002.

[36] U. Dirnagl, C. Iadecola, and M. A. Moskowitz, "Pathobiology of ischaemic stroke: an integrated view," Trends in Neurosciences, vol. 22, no. 9, pp. 391-397, 1999.
[37] E. H. Lo, T. Dalkara, and M. A. Moskowitz, "Mechanisms, challenges and opportunities in stroke," Nature Reviews Neuroscience, vol. 4, no. 5, pp. 399-415, 2003.

[38] D. W. Choi and S. M. Rothman, "The role of glutamate neurotoxicity in hypoxic-ischemic neuronal death," Annual Review of Neuroscience, vol. 13, pp. 171-182, 1990.

[39] V. E. Johnson, J. E. Stewart, F. D. Begbie, J. Q. Trojanowski, D. H. Smith, and W. Stewart, "Inflammation and white matter degeneration persist for years after a single traumatic brain injury," Brain, vol. 136, part 1, pp. 28-42, 2013.

[40] F. Gomez-Pinilla, H. Tram, C. W. Cotman, and M. NietoSampedro, "Neuroprotective effect of MK-801 and U$50488 \mathrm{H}$ after contusive spinal cord injury," Experimental Neurology, vol. 104, no. 2, pp. 118-124, 1989.

[41] M. A. Moskowitz, E. H. Lo, and C. Iadecola, "The science of stroke: mechanisms in search of treatments," Neuron, vol. 67, no. 2, pp. 181-198, 2010.

[42] S. T. Carmichael, "The 3 Rs of stroke biology: radial, relayed, and regenerative," Neurotherapeutics, vol. 13, no. 2, pp. 348$359,2016$.

[43] D. M. Feeney and J. C. Baron, "Diaschisis," Stroke, vol. 17, no. 5, pp. 817-830, 1986.

[44] A. Lipsanen and J. Jolkkonen, "Experimental approaches to study functional recovery following cerebral ischemia," Cellular and Molecular Life Sciences, vol. 68, no. 18, pp. 3007-3017, 2011.

[45] S. C. Cramer and E. P. Bastings, "Mapping clinically relevant plasticity after stroke," Neuropharmacology, vol. 39, no. 5, pp. 842-851, 2000.

[46] M. P. van Meer, K. van der Marel, K. Wang et al., "Recovery of sensorimotor function after experimental stroke correlates with restoration of resting-state interhemispheric functional connectivity," The Journal of Neuroscience, vol. 30, no. 11, pp. 3964-3972, 2010.

[47] M. P. van Meer, K. van der Marel, W. M. Otte, B. van der Sprenkel JW, and R. M. Dijkhuizen, "Correspondence between altered functional and structural connectivity in the contralesional sensorimotor cortex after unilateral stroke in rats: a combined resting-state functional MRI and manganese-enhanced MRI study," Journal of Cerebral Blood Flow and Metabolism, vol. 30, no. 10, pp. 1707-1711, 2010.

[48] J. J. Ohab, S. Fleming, A. Blesch, and S. T. Carmichael, "A neurovascular niche for neurogenesis after stroke," The Journal of Neuroscience, vol. 26, no. 50, pp. 13007-13016, 2006.

[49] S. Li and S. T. Carmichael, "Growth-associated gene and protein expression in the region of axonal sprouting in the aged brain after stroke," Neurobiology of Disease, vol. 23, no. 2, pp. 362-373, 2006.

[50] L. Wang, C. Yu, H. Chen et al., "Dynamic functional reorganization of the motor execution network after stroke," Brain, vol. 133, part 4, pp. 1224-1238, 2010.

[51] K. M. Schoch, S. K. Madathil, and K. E. Saatman, "Genetic manipulation of cell death and neuroplasticity pathways in traumatic brain injury," Neurotherapeutics, vol. 9, no. 2, pp. 323-337, 2012.

[52] C. C. Giza, M. L. Prins, D. A. Hovda, H. R. Herschman, and J. D. Feldman, "Genes preferentially induced by depolarization after concussive brain injury: effects of age and injury severity," Journal of Neurotrauma, vol. 19, no. 4 , pp. $387-402,2002$. 
[53] N. Kobori, G. L. Clifton, and P. Dash, "Altered expression of novel genes in the cerebral cortex following experimental brain injury," Brain Research. Molecular Brain Research, vol. 104, no. 2, pp. 148-158, 2002.

[54] S. C. Cramer and M. Chopp, "Recovery recapitulates ontogeny," Trends in Neurosciences, vol. 23, no. 6, pp. 265-271, 2000.

[55] S. R. Zeiler, R. Hubbard, E. M. Gibson et al., "Paradoxical motor recovery from a first stroke after induction of a second stroke: reopening a postischemic sensitive period," Neurorehabilitation and Neural Repair, vol. 30, no. 8, pp. 794-800, 2016.

[56] A. Shehadah, J. Chen, A. Pal et al., "Human placenta-derived adherent cell treatment of experimental stroke promotes functional recovery after stroke in young adult and older rats," PLoS One, vol. 9, no. 1, article e86621, 2014.

[57] A. W. Dromerick, M. A. Edwardson, D. F. Edwards et al., "Critical periods after stroke study: translating animal stroke recovery experiments into a clinical trial," Frontiers in Human Neuroscience, vol. 9, no. 231, 2015.

[58] A. Pollock, G. Baer, V. Pomeroy, and P. Langhorne, "Physiotherapy treatment approaches for the recovery of postural control and lower limb function following stroke," Cochrane Database of Systematic Reviews, no. 1, p. CD001920, 2007.

[59] B. J. Kollen, S. Lennon, B. Lyons et al., "The effectiveness of the Bobath concept in stroke rehabilitation: what is the evidence?" Stroke, vol. 40, no. 4, pp. e89-e97, 2009.

[60] J. Biernaskie and D. Corbett, "Enriched rehabilitative training promotes improved forelimb motor function and enhanced dendritic growth after focal ischemic injury," The Journal of Neuroscience, vol. 21, no. 14, pp. 5272-5280, 2001.

[61] M. A. Castro-Alamancos and J. Borrel, "Functional recovery of forelimb response capacity after forelimb primary motor cortex damage in the rat is due to the reorganization of adjacent areas of cortex," Neuroscience, vol. 68, no. 3, pp. 793-805, 1995.

[62] J. M. Conner, A. A. Chiba, and M. H. Tuszynski, "The basal forebrain cholinergic system is essential for cortical plasticity and functional recovery following brain injury," Neuron, vol. 46, no. 2, pp. 173-179, 2005.

[63] R. J. Nudo, "Postinfarct cortical plasticity and behavioral recovery," Stroke, vol. 38, Supplement 2, pp. 840-845, 2007.

[64] R. J. Nudo and G. W. Milliken, "Reorganization of movement representations in primary motor cortex following focal ischemic infarcts in adult squirrel monkeys," Journal of Neurophysiology, vol. 75, no. 5, pp. 2144-2149, 1996.

[65] D. Ramanathan, J. M. Conner, and M. H. Tuszynski, "A form of motor cortical plasticity that correlates with recovery of function after brain injury," Proceedings of the National Academy of Sciences of the United States of America, vol. 103, no. 30, pp. 11370-11375, 2006.

[66] S. T. Carmichael, I. Archibeque, L. Luke, T. Nolan, J. Momiy, and S. Li, "Growth-associated gene expression after stroke: evidence for a growth-promoting region in peri-infarct cortex," Experimental Neurology, vol. 193, no. 2, pp. 291-311, 2005.

[67] N. G. Harris, Y. A. Mironova, D. A. Hovda, and R. L. Sutton, "Pericontusion axon sprouting is spatially and temporally consistent with a growth-permissive environment after traumatic brain injury," Journal of Neuropathology and Experimental Neurology, vol. 69, no. 2, pp. 139-154, 2010.
[68] L. I. Benowitz and S. T. Carmichael, "Promoting axonal rewiring to improve outcome after stroke," Neurobiology of Disease, vol. 37, no. 2, pp. 259-266, 2010.

[69] B. Sist, K. Fouad, and I. R. Winship, "Plasticity beyond periinfarct cortex: spinal up regulation of structural plasticity, neurotrophins, and inflammatory cytokines during recovery from cortical stroke," Experimental Neurology, vol. 252, pp. 47-56, 2014.

[70] R. P. Stroemer, T. A. Kent, and C. E. Hulsebosch, "Neocortical neural sprouting, synaptogenesis, and behavioral recovery after neocortical infarction in rats," Stroke, vol. 26, no. 11, pp. 2135-2144, 1995.

[71] S. T. Carmichael and M. F. Chesselet, "Synchronous neuronal activity is a signal for axonal sprouting after cortical lesions in the adult," The Journal of Neuroscience, vol. 22, no. 14, pp. 6062-6070, 2002.

[72] N. Dancause, S. Barbay, S. B. Frost et al., "Extensive cortical rewiring after brain injury," The Journal of Neuroscience, vol. 25, no. 44, pp. 10167-10179, 2005.

[73] K. M. Friel and R. J. Nudo, "Recovery of motor function after focal cortical injury in primates: compensatory movement patterns used during rehabilitative training," Somatosensory \& Motor Research, vol. 15, no. 3, pp. 173-189, 1998.

[74] S. T. Carmichael, "Emergent properties of neural repair: elemental biology to therapeutic concepts," Annals of Neurology, vol. 79, no. 6, pp. 895-906, 2016.

[75] T. A. Jones and D. L. Adkins, "Motor system reorganization after stroke: stimulating and training toward perfection," Physiology (Bethesda), vol. 30, no. 5, pp. 358-370, 2015.

[76] E. J. Plautz, S. Barbay, S. B. Frost et al., "Post-infarct cortical plasticity and behavioral recovery using concurrent cortical stimulation and rehabilitative training: a feasibility study in primates," Neurological Research, vol. 25, no. 8, pp. 801-810, 2003.

[77] N. Dancause, S. Barbay, S. B. Frost et al., "Topographically divergent and convergent connectivity between premotor and primary motor cortex," Cerebral Cortex, vol. 16, no. 8, pp. 1057-1068, 2006.

[78] R. H. Andres, N. Horie, W. Slikker et al., "Human neural stem cells enhance structural plasticity and axonal transport in the ischaemic brain," Brain, vol. 134, part 6, pp. 1777-1789, 2011.

[79] T. A. Jones and T. Schallert, "Overgrowth and pruning of dendrites in adult rats recovering from neocortical damage," Brain Research, vol. 581, no. 1, pp. 156-160, 1992.

[80] T. A. Jones and T. Schallert, "Use-dependent growth of pyramidal neurons after neocortical damage," The Journal of Neuroscience, vol. 14, no. 4, pp. 2140-2152, 1994.

[81] H. W. Cheng, J. Tong, and T. H. McNeill, "Lesion-induced axon sprouting in the deafferented striatum of adult rat," Neuroscience Letters, vol. 242, no. 2, pp. 69-72, 1998.

[82] T. A. Jones, "Multiple synapse formation in the motor cortex opposite unilateral sensorimotor cortex lesions in adult rats," Journal of Comparative Neurology, vol. 414, no. 1, pp. 57-66, 1999.

[83] B. Kolb, G. C. Teskey, and R. Gibb, "Factors influencing cerebral plasticity in the normal and injured brain," Frontiers in Human Neuroscience, vol. 4, no. 204, 2010.

[84] S. Y. Kim, R. P. Allred, D. L. Adkins et al., "Experience with the "good" limb induces aberrant synaptic plasticity in the perilesion cortex after stroke," The Journal of Neuroscience, vol. 35, no. 22, pp. 8604-8610, 2015. 
[85] M. Ariza, J. M. Serra-Grabulosa, C. Junqué et al., "Hippocampal head atrophy after traumatic brain injury," Neuropsychologia, vol. 44, no. 10, pp. 1956-1961, 2006.

[86] W. L. Maxwell, K. Dhillon, L. Harper et al., "There is differential loss of pyramidal cells from the human hippocampus with survival after blunt head injury," Journal of Neuropathology and Experimental Neurology, vol. 62, no. 3, pp. 272-279, 2003.

[87] N. M. Wilson, D. J. Titus, A. A. Oliva Jr, C. Furones, and C. M. Atkins, "Traumatic brain injury upregulates phosphodiesterase expression in the hippocampus," Frontiers in Systems Neuroscience, vol. 10, no. 5, 2016.

[88] A. Sierra, T. Laitinen, O. Gröhn, and A. Pitkänen, "Diffusion tensor imaging of hippocampal network plasticity," Brain Structure \& Function, vol. 220, no. 2, pp. 781-801, 2015.

[89] J. N. Campbell, B. Low, J. E. Kurz, S. S. Patel, M. T. Young, and S. B. Churn, "Mechanisms of dendritic spine remodeling in a rat model of traumatic brain injury," Journal of Neurotrauma, vol. 29, no. 2, pp. 218-234, 2012.

[90] G. S. Griesbach, F. Gomez-Pinilla, and D. A. Hovda, "Time window for voluntary exercise-induced increases in hippocampal neuroplasticity molecules after traumatic brain injury is severity dependent," Journal of Neurotrauma, vol. 24, no. 7, pp. 1161-1171, 2007.

[91] S. W. Scheff, D. A. Price, R. R. Hicks, S. A. Baldwin, S. Robinson, and C. Brackney, "Synaptogenesis in the hippocampal CA1 field following traumatic brain injury," Journal of Neurotrauma, vol. 22, no. 7, pp. 719-732, 2005.

[92] P. K. Dash, S. A. Mach, and A. N. Moore, "The role of extracellular signal-regulated kinase in cognitive and motor deficits following experimental traumatic brain injury," Neuroscience, vol. 114, no. 3, pp. 755-767, 2002.

[93] D. A. Matzilevich, J. M. Rall, A. N. Moore, R. J. Grill, and P. K. Dash, "High-density microarray analysis of hippocampal gene expression following experimental brain injury," Journal of Neuroscience Research, vol. 67, no. 5, pp. 646-663, 2002.

[94] O. Steward, S. L. Vinsant, and L. Davis, "The process of reinnervation in the dentate gyrus of adult rats: an ultrastructural study of changes in presynaptic terminals as a result of sprouting," Journal of Comparative Neurology, vol. 267, no. 2, pp. 203-210, 1988.

[95] T. M. Reeves and O. Steward, "Changes in the firing properties of neurons in the dentate gyrus with denervation and reinnervation: implications for behavioral recovery," Experimental Neurology, vol. 102, no. 1, pp. 37-49, 1988.

[96] O. Steward, "Reorganization of neuronal connections following CNS trauma: principles and experimental paradigms," Journal of Neurotrauma, vol. 6, no. 2, pp. 99-152, 1989.

[97] S. H. Jang and H. D. Lee, "Compensatory neural tract from contralesional fornical body to ipsilesional medial temporal lobe in a patient with mild traumatic brain injury: a case report," American Journal of Physical Medicine \& Rehabilitation, vol. 95, no. 2, pp. e14-e17, 2016.

[98] C. R. Almli and S. Finger, "Toward a definition of recovery of function," in Brain Injury and Recovery: Theoretical and Controversial Issues, C. R. Almli, S. Finger, T. E. LeVere and D. Stein, Eds., pp. 1-14, Springer-Verlag, New York, NY, 1988.

[99] J. A. Long, L. T. Watts, J. Chemello, S. Huang, Q. Shen, and T. Q. Duong, "Multiparametric and longitudinal
MRI characterization of mild traumatic brain injury in rats," Journal of Neurotrauma, vol. 32, no. 8, pp. 598-607, 2015.

[100] A. Encarnacion, N. Horie, H. Keren-Gill, T. M. Bliss, G. K. Steinberg, and M. Shamloo, "Long-term behavioral assessment of function in an experimental model for ischemic stroke," Journal of Neuroscience Methods, vol. 196, no. 2, pp. 247-257, 2011.

[101] W. Almaguer-Melian, D. Mercerón-Martínez, N. PavónFuentes et al., "Erythropoietin promotes neural plasticity and spatial memory recovery in fimbria-fornix-lesioned rats," Neurorehabilitation and Neural Repair, vol. 29, no. 10, pp. 979-988, 2015.

[102] J. Jacqmain, E. T. Nudi, S. Fluharty, and J. S. Smith, "Pre and post-injury environmental enrichment effects functional recovery following medial frontal cortical contusion injury in rats," Behavioural Brain Research, vol. 275, pp. 201-211, 2014.

[103] T. Schallert and T. A. Jones, “"Exuberant” neuronal growth after brain damage in adult rats: the essential role of behavioral experience," Journal of Neural Transplantation \& Plasticity, vol. 4, no. 3, pp. 193-198, 1993.

[104] S. Laurence and D. G. Stein, "Recovery after brain damage and the concept of localization of function," in Recovery from Brain Damage: Research and Theory, S. Finger, Ed., pp. 369-409, Plenum Press, New York, NY, 1978.

[105] B. Kolb, Brain, Plasticity, and Behavior, Lawrence Erlbaum Associates, Mahwah, NJ, USA, 1995.

[106] T. A. Jones, R. P. Allred, S. C. Jefferson et al., "Motor system plasticity in stroke models: intrinsically use-dependent, unreliably useful," Stroke, vol. 44, 6 Supplement 1, pp. S104-S106, 2013.

[107] A. L. Kerr, S. Y. Cheng, and T. A. Jones, "Experience-dependent neural plasticity in the adult damaged brain," Journal of Communication Disorders, vol. 44, no. 5, pp. 538-548, 2011.

[108] J. A. Bell, M. L. Wolke, R. C. Ortez, T. A. Jones, and A. L. Kerr, "Training intensity affects motor rehabilitation efficacy following unilateral ischemic insult of the sensorimotor cortex in C57BL/6 mice," Neurorehabilitation and Neural Repair, vol. 29, no. 6, pp. 590-598, 2015.

[109] A. L. Kerr, M. L. Wolke, J. A. Bell, and T. A. Jones, "Poststroke protection from maladaptive effects of learning with the non-paretic forelimb by bimanual home cage experience in C57BL/6 mice," Behavioural Brain Research, vol. 252, pp. 180-187, 2013.

[110] L. M. Luke, R. P. Allred, and T. A. Jones, "Unilateral ischemic sensorimotor cortical damage induces contralesional synaptogenesis and enhances skilled reaching with the ipsilateral forelimb in adult male rats," Synapse, vol. 54, no. 4, pp. 187-199, 2004.

[111] J. E. Hsu and T. A. Jones, "Time-sensitive enhancement of motor learning with the less-affected forelimb after unilateral sensorimotor cortex lesions in rats," The European Journal of Neuroscience, vol. 22, no. 8, pp. 2069-2080, 2005.

[112] D. A. Kozlowski, J. L. Leasure, and T. Schallert, "The control of movement following traumatic brain injury," Comprehensive Physiology, vol. 3, no. 1, pp. 121-139, 2013.

[113] B. Zhang, Q. He, Y. Y. Li et al., "Constraint-induced movement therapy promotes motor function recovery and downregulates phosphorylated extracellular regulated protein kinase expression in ischemic brain tissue of rats," Neural Regeneration Research, vol. 10, no. 12, pp. 2004-2010, 2015. 
[114] T. A. Jones, D. J. Liput, E. L. Maresh et al., "Use-dependent dendritic regrowth is limited after unilateral controlled cortical impact to the forelimb sensorimotor cortex," Journal of Neurotrauma, vol. 29, no. 7, pp. 1455-1468, 2012.

[115] D. L. Adkins, L. Ferguson, S. Lance et al., "Combining multiple types of motor rehabilitation enhances skilled forelimb use following experimental traumatic brain injury in rats," Neurorehabilitation and Neural Repair, vol. 29, no. 10, pp. 989-1000, 2015.

[116] S. C. Jefferson, E. R. Clayton, N. A. Donlan, D. A. Kozlowski, T. A. Jones, and D. L. Adkins, "Cortical stimulation concurrent with skilled motor training improves forelimb function and enhances motor cortical reorganization following controlled cortical impact," Neurorehabilitation and Neural Repair, vol. 30, no. 2, pp. 155-158, 2016.

[117] H. L. Combs, T. A. Jones, D. A. Kozlowski, and D. L. Adkins, "Combinatorial motor training results in functional reorganization of remaining motor cortex after controlled cortical impact in rats," Journal of Neurotrauma, vol. 33, no. 8, pp. 741-747, 2016.

[118] J. Z. Guo, A. R. Graves, W. W. Guo et al., "Cortex commands the performance of skilled movement," eLife, vol. 4," no. e10774, 2015.

[119] E. V. Shanina, T. Schallert, O. W. Witte, and C. Redecker, "Behavioral recovery from unilateral photothrombotic infarcts of the forelimb sensorimotor cortex in rats: role of the contralateral cortex," Neuroscience, vol. 139, no. 4, pp. 1495-1506, 2006.

[120] R. P. Allred, M. A. Maldonado, J. E. Hsu And, and T. A. Jones, "Training the "less-affected" forelimb after unilateral cortical infarcts interferes with functional recovery of the impaired forelimb in rats," Restorative Neurology and Neuroscience, vol. 23, no. 5-6, pp. 297-302, 2005.

[121] R. P. Allred, D. L. Adkins, M. T. Woodlee et al., "The vermicelli handling test: a simple quantitative measure of dexterous forepaw function in rats," Journal of Neuroscience Methods, vol. 170, no. 2, pp. 229-244, 2008.

[122] R. P. Allred, C. H. Cappellini, and T. A. Jones, "The "good" limb makes the "bad" limb worse: experience-dependent interhemispheric disruption of functional outcome after cortical infarcts in rats," Behavioral Neuroscience, vol. 124, no. 1, pp. 124-132, 2010.

[123] R. P. Allred and T. A. Jones, "Maladaptive effects of learning with the less-affected forelimb after focal cortical infarcts in rats," Experimental Neurology, vol. 210, no. 1, pp. 172-181, 2008.

[124] J. Clarke, K. D. Langdon, and D. Corbett, "Early poststroke experience differentially alters periinfarct layer II and III cortex," Journal of Cerebral Blood Flow and Metabolism, vol. 34, no. 4, pp. 630-637, 2014.

[125] R. P. Allred and T. A. Jones, "Experience-a double edged sword for restorative neural plasticity after brain damage," Future Neurology, vol. 3, no. 2, pp. 189-198, 2008.

[126] T. A. Jones, R. P. Allred, D. L. Adkins, J. E. Hsu, A. O’Bryant, and M. A. Maldonado, "Remodeling the brain with behavioral experience after stroke," Stroke, vol. 40, Supplement 3, pp. S136-S138, 2009.

[127] E. J. Plautz, S. Barbay, S. B. Frost et al., "Effects of subdural monopolar cortical stimulation paired with rehabilitative training on behavioral and neurophysiological recovery after cortical ischemic stroke in adult squirrel monkeys,"
Neurorehabilitation and Neural Repair, vol. 30, no. 2, pp. 159-172, 2016.

[128] F. Buma, G. Kwakkel, and N. Ramsey, "Understanding upper limb recovery after stroke," Restorative Neurology and Neuroscience, vol. 31, no. 6, pp. 707-722, 2013.

[129] M. Murray and M. E. Goldberger, "Restitution of function and collateral sprouting in the cat spinal cord: the partially hemisected animal," Journal of Comparative Neurology, vol. 158, no. 1, pp. 19-36, 1974.

[130] M. E. Goldberger and M. Murray, "Restitution of function and collateral sprouting in the cat spinal cord: the deafferented animal," Journal of Comparative Neurology, vol. 158, no. 1, pp. 37-53, 1974.

[131] K. H. Lee, "The role of compensatory movements patterns in spontaneous recovery after stroke," Journal of Physical Therapy Science, vol. 27, no. 9, pp. 2671-2673, 2015.

[132] Y. Murata, N. Higo, T. Hayashi et al., “Temporal plasticity involved in recovery from manual dexterity deficit after motor cortex lesion in macaque monkeys," The Journal of Neuroscience, vol. 35, no. 1, pp. 84-95, 2015.

[133] I. Q. Whishaw, S. M. Pellis, B. P. Gorny, and V. C. Pellis, “The impairments in reaching and the movements of compensation in rats with motor cortex lesions: an endpoint, videorecording, and movement notation analysis," Behavioural Brain Research, vol. 42, no. 1, pp. 77-91, 1991.

[134] I. Q. Whishaw, M. Alaverdashvili, and B. Kolb, “The problem of relating plasticity and skilled reaching after motor cortex stroke in the rat," Behavioural Brain Research, vol. 192, no. 1, pp. 124-136, 2008.

[135] C. A. Erickson, O. A. Gharbawie, and I. Q. Whishaw, "Attempt-dependent decrease in skilled reaching characterizes the acute postsurgical period following a forelimb motor cortex lesion: an experimental demonstration of learned nonuse in the rat," Behavioural Brain Research, vol. 179, no. 2, pp. 208-218, 2007.

[136] M. Alaverdashvili, A. Foroud, D. H. Lim, and I. Q. Whishaw, "“Learned baduse" limits recovery of skilled reaching for food after forelimb motor cortex stroke in rats: a new analysis of the effect of gestures on success," Behavioural Brain Research, vol. 188, no. 2, pp. 281-290, 2008.

[137] P. Raghavan, "Upper limb motor impairment after stroke," Physical Medicine and Rehabilitation Clinics of North America, vol. 26, no. 4, pp. 599-610, 2015.

[138] A. L. Kerr, K. A. Cheffer, M. C. Curtis, and A. Rodriguez, "Long-term deficits of the paretic limb follow post-stroke compensatory limb use in C57BL/6 mice," Behavioural Brain Research, vol. 303, pp. 103-108, 2016.

[139] J. P. Rauschecker, "Compensatory plasticity and sensory substitution in the cerebral cortex," Trends in Neurosciences, vol. 18, no. 1, pp. 36-43, 1995.

[140] I. Q. Whishaw, J. A. Zaborowski, and B. Kolb, "Postsurgical enrichment aids adult hemidecorticate rats on a spatial navigation task," Behavioral and Neural Biology, vol. 42, no. 2, pp. 183-190, 1984.

[141] B. J. Clark, J. P. Rice, K. G. Akers, F. T. Candelaria-Cook, J. S. Taube, and D. A. Hamilton, "Lesions of the dorsal tegmental nuclei disrupt control of navigation by distal landmarks in cued, directional, and place variants of the Morris water task," Behavioral Neuroscience, vol. 127, no. 4, pp. 566-581, 2013.

[142] M. Alaverdashvili, D. H. Lim, and I. Q. Whishaw, "No improvement by amphetamine on learned non-use, attempts, 
success or movement in skilled reaching by the rat after motor cortex stroke," The European Journal of Neuroscience, vol. 25, no. 11, pp. 3442-3452, 2007.

[143] M. S. Yong and K. Hwangbo, "Skilled reach training influences brain recovery following intracerebral hemorrhage in rats," Journal of Physical Therapy Science, vol. 26, no. 3, pp. 405-407, 2014.

[144] E. Taub, "Harnessing brain plasticity through behavioral techniques to produce new treatments in neurorehabilitation," The American Psychologist, vol. 59, no. 8, pp. 692704, 2004.

[145] V. W. Mark and E. Taub, "Constraint-induced movement therapy for chronic stroke hemiparesis and other disabilities," Restorative Neurology and Neuroscience, vol. 22, no. 3-5, pp. 317-336, 2004.

[146] S. Zhao, M. Zhao, T. Xiao, J. Jolkkonen, and C. Zhao, "Constraint-induced movement therapy overcomes the intrinsic axonal growth-inhibitory signals in stroke rats," Stroke, vol. 44, no. 6, pp. 1698-1705, 2013.

[147] S. S. Zhao, Y. Zhao, T. Xiao, M. Zhao, J. Jolkkonen, and C. S. Zhao, "Increased neurogenesis contributes to the promoted behavioral recovery by constraint-induced movement therapy after stroke in adult rats," CNS Neuroscience \& Therapeutics, vol. 19, no. 3, pp. 194-196, 2013.

[148] M. Nishibe, E. T. Urban 3rd, S. Barbay, and R. J. Nudo, "Rehabilitative training promotes rapid motor recovery but delayed motor map reorganization in a rat cortical ischemic infarct model," Neurorehabilitation and Neural Repair, vol. 29, no. 5, pp. 472-482, 2015.

[149] J. J. Braun, "Time and recovery from brain damage," in Recovery from Brain Damage: Research and Theory, S. Finger, Ed., pp. 369-409, Plenum Press, New York, NY, 1978.

[150] P. Ramos-Cabrer, C. Justicia, D. Wiedermann, and M. Hoehn, "Stem cell mediation of functional recovery after stroke in the rat," PLoS One, vol. 5, no. 9, article e12779, 2010.

[151] D. Nunnari, P. Bramanti, and S. Marino, "Cognitive reserve in stroke and traumatic brain injury patients," Neurological Sciences, vol. 35, no. 10, pp. 1513-1518, 2014.

[152] Y. Stern, “Cognitive reserve," Neuropsychologia, vol. 47, no. 10, pp. 2015-2028, 2009.

[153] Y. Stern, C. Habeck, J. Moeller et al., "Brain networks associated with cognitive reserve in healthy young and old adults," Cerebral Cortex, vol. 15, no. 4, pp. 394-402, 2005.

[154] L. J. Whalley, I. J. Deary, C. L. Appleton, and J. M. Starr, "Cognitive reserve and the neurobiology of cognitive aging," Ageing Research Reviews, vol. 3, no. 4, pp. 369382,2004

[155] N. Scarmeas and Y. Stern, "Cognitive reserve and lifestyle," Journal of Clinical and Experimental Neuropsychology, vol. 25, no. 5, pp. 625-633, 2003.

[156] A. D. Murray, R. T. Staff, C. J. McNeil et al., "The balance between cognitive reserve and brain imaging biomarkers of cerebrovascular and Alzheimer's diseases," Brain, vol. 134, part 12, pp. 3687-3696, 2011.

[157] J. S. Elkins, W. T. Longstreth Jr, T. A. Manolio, A. B. Newman, R. A. Bhadelia, and S. C. Johnston, "Education and the cognitive decline associated with MRI-defined brain infarct," Neurology, vol. 67, no. 3, pp. 435-440, 2006.

[158] T. B. Fay, K. O. Yeates, H. G. Taylor et al., "Cognitive reserve as a moderator of postconcussive symptoms in children with complicated and uncomplicated mild traumatic brain injury," Journal of the International Neuropsychological Society, vol. 16, no. 1, pp. 94-105, 2010.

[159] E. B. Schneider, S. Sur, V. Raymont et al., "Functional recovery after moderate/severe traumatic brain injury: a role for cognitive reserve?" Neurology, vol. 82, no. 18, pp. 1636-1642, 2014.

[160] J. E. Farmer, S. M. Kanne, J. S. Haut, J. Williams, B. Johnstone, and K. Kirk, "Memory functioning following traumatic brain injury in children with premorbid learning problems," Developmental Neuropsychology, vol. 22, no. 2, pp. 455-469, 2002.

[161] P. Satz, "Brain reserve capacity on symptom onset after brain injury: a formulation and review of evidence for threshold theory," Neuropsychology, vol. 7, no. 3, pp. 273-295, 1993.

[162] M. Dennis, K. O. Yeates, H. G. Taylor, and J. M. Fletcher, "Brain reserve capacity, cognitive reserve capacity, and agebased functional plasticity after congenital and acquired brain injury in children," in Cognitive Reserve: Theory and Applications, Y. Stern, Ed., pp. 53-83, Taylor \& Francis, Philadelphia, PA, 2007.

[163] D. G. Flood and P. D. Coleman, "Neuron numbers and sizes in aging brain: comparisons of human, monkey, and rodent data," Neurobiology of Aging, vol. 9, no. 5-6, pp. 453-463, 1988.

[164] J. L. Humm, D. A. Kozlowski, D. C. James, J. E. Gotts, and T. Schallert, "Use-dependent exacerbation of brain damage occurs during an early post-lesion vulnerable period," Brain Research, vol. 783, no. 2, pp. 286-292, 1998.

[165] D. A. Kozlowski, D. C. James, and T. Schallert, "Usedependent exaggeration of neuronal injury after unilateral sensorimotor cortex lesions," The Journal of Neuroscience, vol. 16, no. 15, pp. 4776-4786, 1996.

[166] M. T. Woodlee and T. Schallert, "The interplay between behavior and neurodegeneration in rat models of Parkinson's disease and stroke," Restorative Neurology and Neuroscience, vol. 22, no. 3-5, pp. 153-161, 2004.

[167] G. S. Griesbach, F. Gomez-Pinilla, and D. A. Hovda, "The upregulation of plasticity-related proteins following TBI is disrupted with acute voluntary exercise," Brain Research, vol. 1016, no. 2, pp. 154-162, 2004.

[168] G. S. Griesbach, D. A. Hovda, R. Molteni, A. Wu, and F. Gomez-Pinilla, "Voluntary exercise following traumatic brain injury: brain-derived neurotrophic factor upregulation and recovery of function," Neuroscience, vol. 125, no. 1, pp. 129-139, 2004.

[169] Y. J. Sim, S. S. Kim, J. Y. Kim, M. S. Shin, and C. J. Kim, "Treadmill exercise improves short-term memory by suppressing ischemia-induced apoptosis of neuronal cells in gerbils," Neuroscience Letters, vol. 372, no. 3, pp. 256261, 2004

[170] Y. J. Sim, H. Kim, J. Y. Kim et al., "Long-term treadmill exercise overcomes ischemia-induced apoptotic neuronal cell death in gerbils," Physiology \& Behavior, vol. 84, no. 5, pp. 733-738, 2005.

[171] J. Biernaskie, G. Chernenko, and D. Corbett, "Efficacy of rehabilitative experience declines with time after focal ischemic brain injury," The Journal of Neuroscience, vol. 24, no. 5, pp. 1245-1254, 2004.

[172] B. A. Norrie, J. M. Nevett-Duchcherer, and M. A. Gorassini, "Reduced functional recovery by delaying motor training after spinal cord injury," Journal of Neurophysiology, vol. 94, no. 1, pp. 255-264, 2005. 
[173] S. Barbay, E. J. Plautz, K. M. Friel et al., "Behavioral and neurophysiological effects of delayed training following a small ischemic infarct in primary motor cortex of squirrel monkeys," Experimental Brain Research, vol. 169, no. 1, pp. 106-116, 2006.

[174] K. A. Tennant, D. L. Adkins, M. D. Scalco, N. A. Donlan, A. L. Asay, and N. Thomas, "The effects of duration and intensity of motor skill training on plasticity of the forelimb representation in the motor cortex of C57BL/6 mice," in Society for Neuroscience, San Diego, CA, 2010.

[175] C. L. MacLellan, M. B. Keough, S. Granter-Button, G. A. Chernenko, S. Butt, and D. Corbett, "A critical threshold of rehabilitation involving brain-derived neurotrophic factor is required for poststroke recovery," Neurorehabilitation and Neural Repair, vol. 25, no. 8, pp. 740-748, 2011.

[176] L. B. Merabet, R. Hamilton, G. Schlaug et al., "Rapid and reversible recruitment of early visual cortex for touch," PLoS One, vol. 3, no. 8, article e3046, 2008.

[177] B. Kolb, R. Brown, A. Witt-Lajeunesse, and R. Gibb, "Neural compensations after lesion of the cerebral cortex," Neural Plasticity, vol. 8, no. 1-2, pp. 1-16, 2001.

[178] R. J. Nudo, "Mechanisms for recovery of motor function following cortical damage," Current Opinion in Neurobiology, vol. 16, no. 6, pp. 638-644, 2006.

[179] R. J. Nudo, G. W. Milliken, W. M. Jenkins, and M. M. Merzenich, "Use-dependent alterations of movement representations in primary motor cortex of adult squirrel monkeys," The Journal of Neuroscience, vol. 16, no. 2, pp. 785-807, 1996.

[180] B. Kolb, "Overview of cortical plasticity and recovery from brain injury," Physical Medicine and Rehabilitation Clinics of North America, vol. 14, Supplement 1, pp. S7-S25, 2003. 

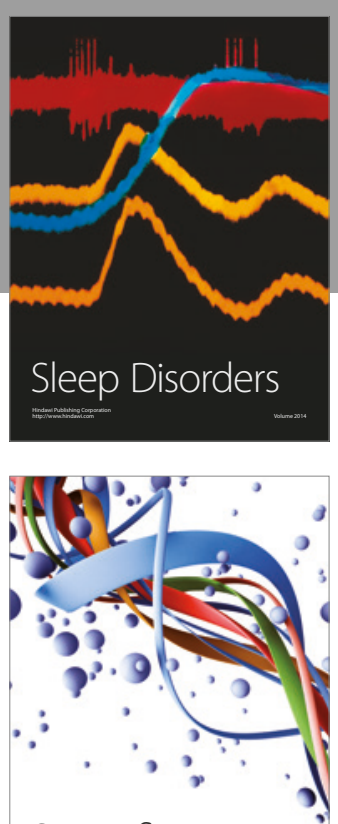

Scientifica
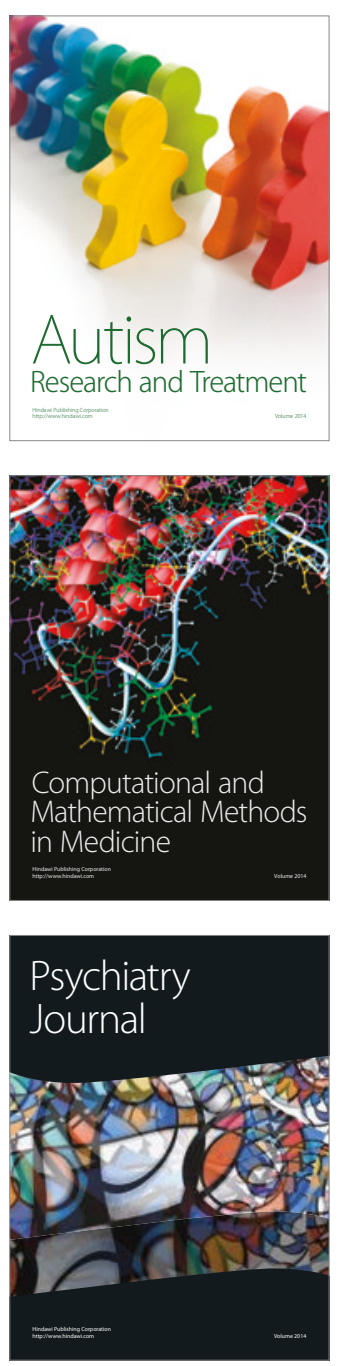
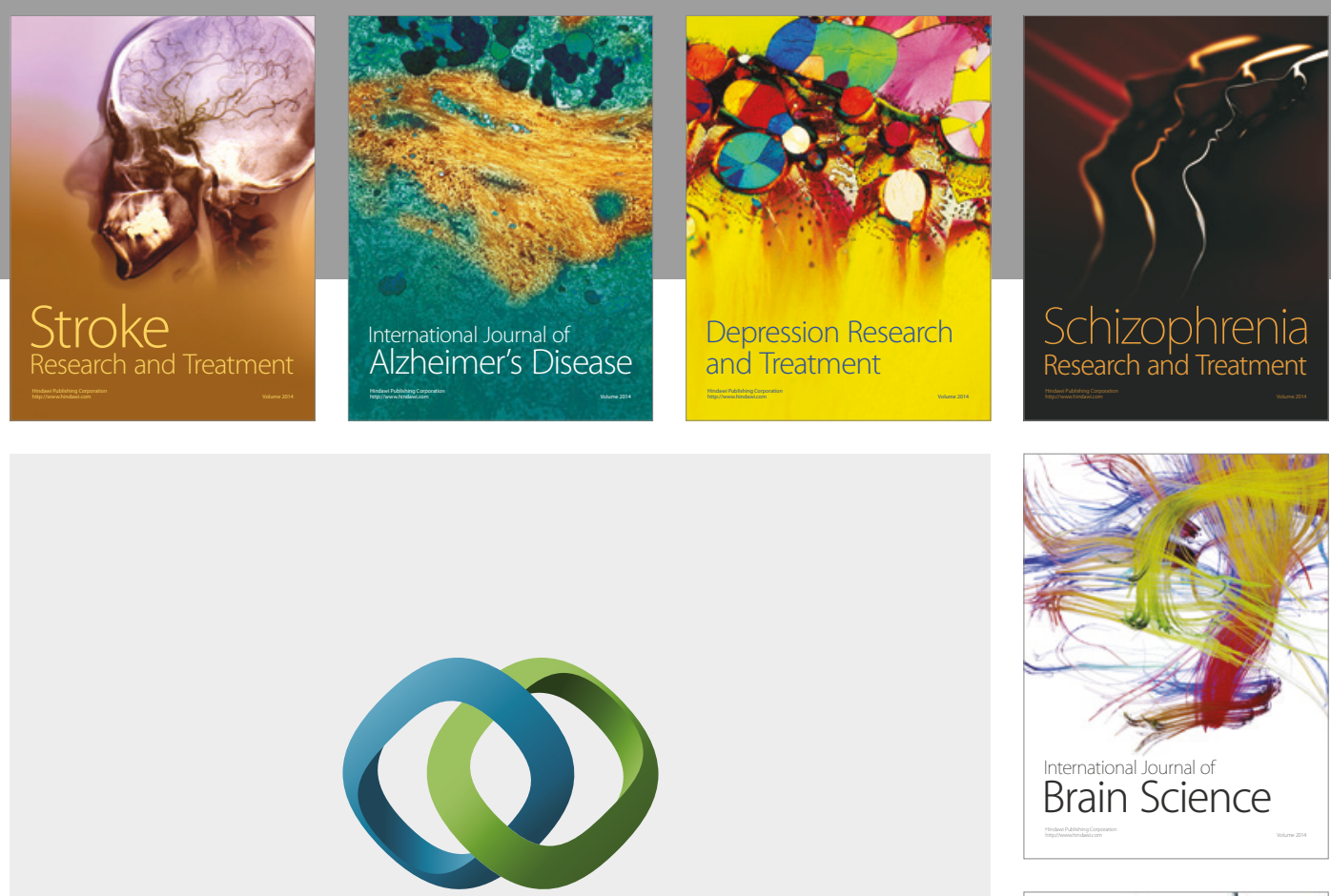

\section{Hindawi}

Submit your manuscripts at

https://www.hindawi.com
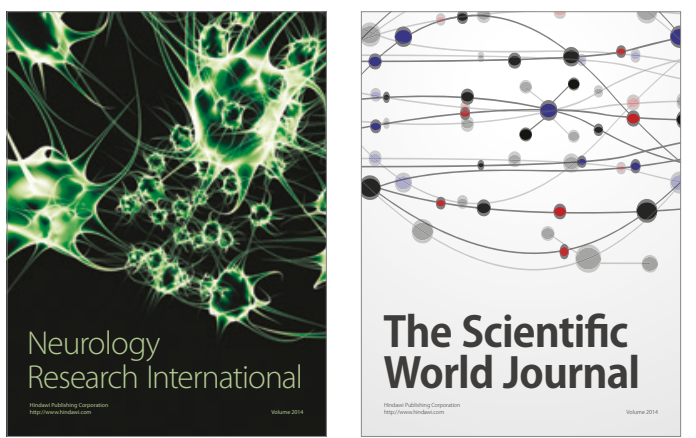

The Scientific World Journal

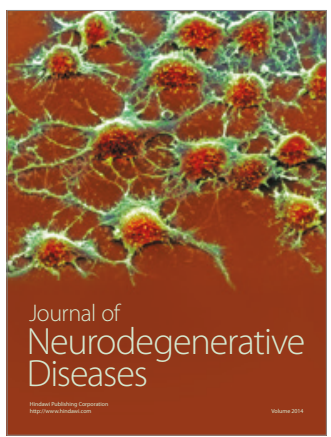

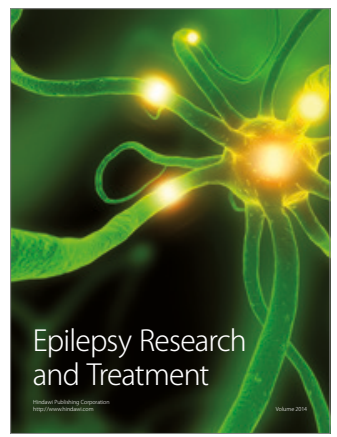

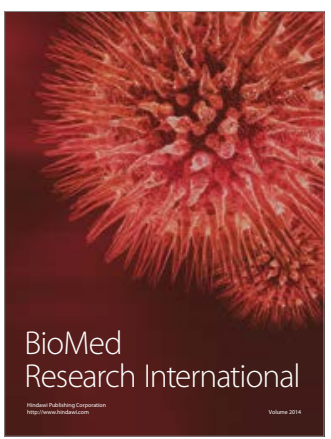

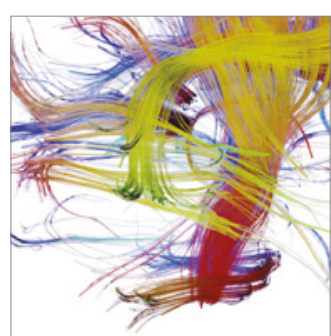

Brain Science

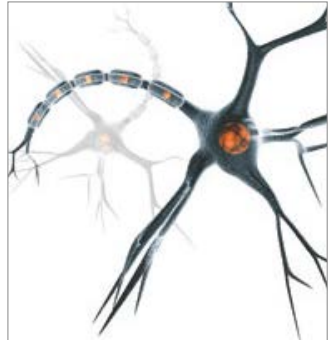

Neural Plasticity
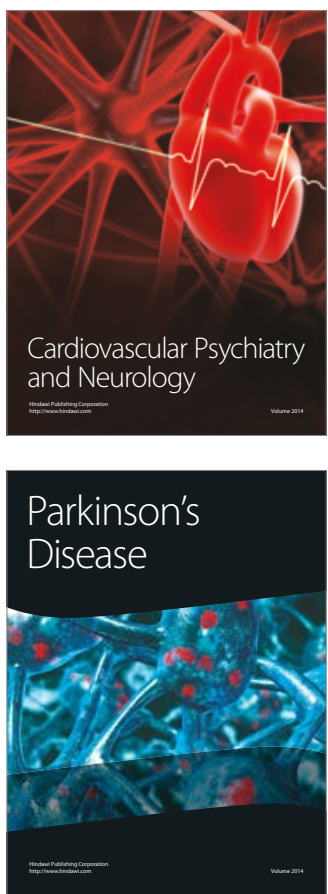